\title{
Editorial: Innovative Methods for Non-invasive Monitoring of Hydrological Processes From Field to Catchment Scale
}

\author{
Heye R. Bogena ${ }^{1 *}$, Virginia Strati ${ }^{2,3}$, Andreas Güntner ${ }^{4,5}$, Clara C. Chew ${ }^{6}$ and \\ Martin Schrön ${ }^{7}$ \\ ${ }^{1}$ Forschungszentrum Jülich GmbH, Institute of Bio- and Geosciences, Agrosphere Institute (IBG-3), Jülich, Germany, \\ ${ }^{2}$ Department of Physics and Earth Sciences, Università of Ferrara, Ferrara, Italy, ${ }^{3}$ Istituto Nazionale di Fisica Nucleare, \\ Ferrara Section, Ferrara, Italy, ${ }^{4}$ GFZ German Research Centre for Geosciences, Potsdam, Germany, ${ }^{5}$ Institute of \\ Environmental Science and Geography, University of Potsdam, Potsdam, Germany, ${ }^{6}$ Earth Observation and Data Science, \\ University Corporation for Atmospheric Research (UCAR), Boulder, NV, United States, ${ }^{7}$ Helmholtz Centre for Environmental \\ Research (UFZ), Leipzig, Germany
}

Keywords: soil moisture, non-invasive measurement techniques, cosmic-ray neutron probes, field scale, catchment, land surface

\section{Editorial on the Research Topic}

\section{OPEN ACCESS}

Edited by:

Luca Brocca,

National Research Council (CNR), Italy

Reviewed by:

Tiejun Wang,

Tianjin University, China Georgia Papacharalampous, Roma Tre University, Italy

*Correspondence:

Heye R. Bogena

h.bogena@fz-juelich.de

Specialty section: This article was submitted to Water and Hydrocomplexity, a section of the journal

Frontiers in Water

Received: 14 December 2020 Accepted: 16 February 2021

Published: 16 March 2021

Citation:

Bogena HR, Strati V, Güntner A, Chew CC and Schrön M (2021)

Editorial: Innovative Methods for Non-invasive Monitoring of Hydrological Processes From Field to

Catchment Scale.

Front. Water 3:641458.

doi: 10.3389/frwa.2021.641458
Innovative Methods for Non-invasive Monitoring of Hydrological Processes From Field to Catchment Scale

The advancement of hydrological research relies on innovative methods to determine water states and fluxes at high spatiotemporal resolution and covering large areas. The emergence of novel measurement techniques has been and will continue to be an important driver for the ability to analyze hydrological processes and to evaluate process-based models (Bogena et al., 2015). Soil moisture is an important state variable as it controls the exchange of water and energy between the land surface and the atmosphere. Information on soil moisture dynamics is also important for agricultural practices and management, and for a better understanding of biogeochemical, vadose zone, and atmospheric processes. To date, soil moisture is mostly measured with in-situ electromagnetic soil moisture sensors for a relatively small volume of soil (Jonard et al., 2018). However, soil moisture shows strong spatial variability at the field scale that is not well-covered by in-situ sensors (Vereecken et al., 2014). Recent advances in non-invasive measurement techniques, such as cosmic-ray neutron probes (CRNP), GNSS (global navigation satellite system) reflectometry, ground-based microwave radiometry, gamma-ray monitoring and terrestrial gravimetry, allow continuous non-invasive soil moisture measurements that integrate over the field to the catchment scale (Bogena et al., 2015).

The purpose of this Research Topic is to share recent advances in CRNP-based techniques that detect fluctuations of neutron intensities at the land surface resulting from high-energy particles from space and hydrogen distribution in and on soil at the land surface to provide continuous noninvasive measurements of soil moisture dynamics from the field to catchment scale. This Research Topic features seven articles, which are briefly introduced in the following:

Franz et al. applied established data analysis approaches to deriving novel CRNP data products: smoothed soil moisture time series, landscape average rainfall, and root zone soil moisture. The authors take a significant step forward by enhancing CRNS soil moisture data to provide stakeholders with value-added data products. The presented results could serve as a critical step toward the adoption of CRNP data for practical applications.

Jakobi et al. quantified the uncertainty in soil moisture estimation from cosmic ray neutron measurements with an easy-to-use 3rd order Taylor expansion approach. This approach is 
particularly useful for neutron rover measurements, since the soil moisture estimates obtained with this approach are typically more uncertain than those obtained with stationary CRNPs. Thus, the presented method has great potential for planning and evaluating rover experiments and to find a suitable trade-off between measurement accuracy, aggregation, and the associated spatial resolution of the resulting soil moisture products. The authors also published a companion Corrigendum paper (Jakobi et al.).

Bogena et al. used long-term CRNP measurements in the Pinios Hydrologic Observatory (PHO), Greece, to test different methods for converting neutron count rates to snow pack characteristics. These methods include linear regression methods based on thermal and epithermal neutrons, the standard N0calibration function, and a physics-based calibration approach. They found that the N0-calibration function and the physicsbased calibration performed the best and the ratio of thermal to epithermal neutrons performed the worst. They concluded that CRNP-based SWE (snow water equivalent) determination at the field scale is a potential alternative to established methods based on point-based snow depth observations.

Nasta et al. compared data from CRNP and SoilNet wireless in-situ sensor networks at two sites in the Alento catchment, Italy. They found discrepancies in the data of the two sensor types related to the effects of the time-varying vertical measurement footprint of the CRNP. Furthermore, they showed that the bimodality of the Soil Moisture Index (SMI) derived from SoilNet data was not well-captured by CRNP and that SMI contrasts between the two different test sites can be explained by soil texture or terrain characteristics. Finally, the authors also derived field-scale water retention functions from CRNP and SoilNet data for the analysis of hydrological processes.

Weimar et al. examined critical properties of neutron detectors specifically designed for CRNP applications. The authors introduced a large-scale detector setup by optimizing the moderator thickness and the spatial dimensions of the moderator housing in order to increase the count rate. They also discussed the effect of non-neutron radiation and its influence on the overall signal quality. The novel detection system achieves count rates that are much higher than usual systems with higher signalto-noise ratio. Moreover, the lower relative statistical uncertainty leads to more precise soil moisture measurements at short time scales.

González-Sanchis et al. compared the capability of in-situ soil sensors and CRNP in assessing soil water dynamics as

\section{REFERENCES}

Bogena, H. R., Huisman, J. A., Hübner, C., Kusche, J., Jonard, F., Vey, S., et al. (2015). Emerging methods for non-invasive sensing of soil moisture dynamics from field to catchment scale: a review. WIREs Water 2, 635-647. doi: 10.1002/wat2. 1097

Jonard, F., Bogena, H., Caterina, D., Garré S., Klotzsche, A., Monerris, A., et al. (2018). "Ground-based soil moisture determination," in Observation and Measurement. eds X. Li and H. Vereecken (Berlin; Heidelberg: Springer, Ecohydrology). doi: 10.1007/978-3-662-4787 $1-4 \_2-2$

Vereecken, H., Huisman, J. A., Pachepsky, Y., Montzka, C., van der Kruk, J., Bogena, H., et al. (2014). On the spatio-temporal dynamics of soil water a key variable that reflects the effects of forest management in a semi-arid environment. To this end, two experimental plots were established in Sierra Calderona, Spain, in a post-fire regeneration Aleppo pine forest. They found that the performance of CRNP was better under semi-arid than under extremely dry conditions. Forest biomass and litter layer led to an overestimation of CRNP-derived soil moisture. Both sensor systems were capable to reproduce tree transpiration affected by soil moisture, environmental variables, and thinning, with CRNP being affected by atmospheric forcing.

Köhli et al. proposed a new analytical method to estimate the neutron response to soil moisture and air humidity. Comparing two Monte-Carlo neutron transport simulations, URANOS and MCNP, their findings revealed a systematic deviation of the standard relationship between the neutron count rate and soil moisture especially for extremely dry conditions. The authors also discussed the importance of detector-specific response functions, various model concepts and atmospheric humidity. The new analytical relationship has been tested at two exemplary CRNP monitoring sites and it outperformed the hitherto standard approach.

We are convinced that the presented advances in CRNPbased techniques will improve the description of local-scale processes related to hydrological fluxes and storage variations, which is of key importance to reduce the large uncertainties that are still present in large-scale models used to predict soil water dynamics.

\section{AUTHOR CONTRIBUTIONS}

HB had the idea for this Research Topic and has invited the guest editors. HB, MS, VS, AG, and CC invited authors and did article review and editing. $\mathrm{HB}$ wrote the editorial, which was then edited by MS, VS, AG, and CC. All authors contributed to the article and approved the submitted version.

\section{ACKNOWLEDGMENTS}

We would like to thank the authors for their contributions and patience, the many reviewers for their time and effort, the Specialty Chief Editor, Harrie-Jan Hendricks Franssen, for organizing the entire review process, and the Frontiers editorial team for their administrative and logistical support throughout the process.

content at the field scale. J. Hydrol. 516, 76-96. doi: 10.1016/j.jhydrol.2013. 11.061

Conflict of Interest: The authors declare that the research was conducted in the absence of any commercial or financial relationships that could be construed as a potential conflict of interest.

Copyright (C) 2021 Bogena, Strati, Güntner, Chew and Schrön. This is an open-access article distributed under the terms of the Creative Commons Attribution License (CC $B Y)$. The use, distribution or reproduction in other forums is permitted, provided the original author(s) and the copyright owner(s) are credited and that the original publication in this journal is cited, in accordance with accepted academic practice. No use, distribution or reproduction is permitted which does not comply with these terms. 